\title{
An Analysis Of The Effectiveness Of Podcasting As A Supplemental Instructional Tool: A Pilot Study
}

Russell Baker, Jacksonville University Jeffery Harrison, Jacksonville University

Barry Thornton, Jacksonville University Rhett Yates, Jacksonville University

\begin{abstract}
Podcasting is the creation of audio or video files for use on iPods and other MP3 players. It allows the user to view or listen to downloadable files wherever or whenever desired. In higher education, podcasting is experiencing extraordinary growth. While a significant volume of literature exists both lauding and lamenting the incorporation of podcasts into university curricula, the authors were unable to find any empirical studies in either the academic or popular press evaluating any benefits or detriments attributable to educational applications of podcasting. This paper presents the pilot for an empirical study of the effectiveness of podcasting as a course supplement.
\end{abstract}

\section{INTRODUCTION}

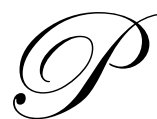

rofessors in universities nationwide are introducing a new teaching technology into their courses. Application of the technology in the classroom can replace large, impersonal lectures, supplement course materials, and allow the students access to course information any time or anywhere. Although as of this writing educational applications of this new technology, podcasting, have existed just over a year, it is now as popular as fraternity parties and football games. At Purdue University "students have downloaded 40,000 lectures since the start of the semester — not bad for a school with an enrollment of 38,000. Drexel, Stanford, Duke and American University have begun podcasting programs too" (Tyre, 2005).

Podcasting is the creation of audio or video files for use on ipods and other mp3 players. It allows the user to view or listen to downloadable files wherever or whenever desired (Morris, 2006). It is a portmanteau, or compound word, combining iPod and broadcasting (Brenner, 2005). The name is somewhat of a misnomer in that podcasting does not involve broadcasting and an iPod is not required. Podcasts are downloaded from the web and may be played on most $\mathrm{mp} 3$ players as well as any computer through free software available from Apple. Podcasting originally was designed for audio. However, the new video enabled iPods permits viewing of film, television, and a variety of other visual media. Over 32 million iPods were sold in 2005, or approximately one per second (Castelluccio, 2006).

Podcasts are mp3 format files created using an RSS 2.0 (really simple syndication) feed. The technology permits downloading and presentation of lectures, music, other audio or video content. Both individual and subscription podcasts are available to users online. Unlike streaming video or audio, podcasting puts the file onto the user's device. This enables viewing or listening at the user's discretion.

In higher education, podcasting is experiencing extraordinary growth. According to Mark Benno, Curriculum Evangelist for Apple Computers, a Google search for "podcasting" in 2004 would have received 24 hits (Benno, 2006). A search today would yield more than 52 million hits (Google, 2006). Despite this amazing growth, many educators are still searching for the best way to employ podcasting in their academic regimen as well as the 
most efficient way to initiate a podcasting program. ITunes $U$ is a recently added service that Apple offers to universities. "It's a pilot project that offers college lectures over a software and service package that Apple makes available to schools. Stanford University not only offers free access to some of the lectures, but it also provides audio broadcasts to some sporting events" (Castelluccio, 2006)." The growth, understanding and acceptance of this technology are clearly evident to the students currently entering our colleges and universities. According to a study at Jacksonville University, approximately $67 \%$ of the 350 students enrolled in the college of business own some type of mp3 (iPod) player (JU Survey, 2006).

While a significant volume of literature exists both lauding and lamenting the incorporation of podcasts into university curricula, the authors were unable to find any empirical studies in either the academic or popular press evaluating any benefits or detriments attributable to educational applications of podcasting. Therein lays the purpose of this study.

\section{PURPOSE OF STUDY}

The purpose of this study is to empirically evaluate the benefits of incorporating podcasting into a university course. The study conducted will attempt to answer the following research questions:

1. Does the inclusion of podcasts as a supplemental tool in a blended university course have an effect on student learning outcomes based on course grade?

2. Do students have a favorable, neutral, or unfavorable impression of podcasting as an educational tool after participating in a course that incorporates podcasts as a required part of the curriculum?

It is anticipated that during the course of this study, additional questions will develop. For this reason and to avoid bias in the study, the authors have chosen not to develop hypotheses.

\section{LITERATURE REVIEW}

As previously stated, the authors were unable to ascertain any empirical studies related to the affect of podcasting in higher education. However, a plethora of literature exists discussing the explosive growth of podcasting and subjective evaluations of its benefits.

A Google search of "podcasts" in April of 2006 produced more than 125 million hits and yet podcasting is still considered a new phenomenon (Bradbury, 2006). Apple CEO Steve Jobs calls podcasting "the next generation of radio (Barnett, 2005)." According to Gardner Campbell, "Part of the reason podcasting has taken off so quickly is that there's very little worth listening to on the radio." He goes on to state: "The endurance of radio, or idea of radio, is the other part and is a major reason why podcasting has such potential value in teaching and learning." Podcasting is finding its way into many parts of society and the opportunities are vast (Barnett, 2005). Education is one of these avenues. In the fall of 2004 Duke University gave all new students an iPod (Barnett, 2005). The University has since incorporated podcasting into its curriculum. "Lectures can be disseminated through podcasts, teachers can listen to professional development audio files, and students can submit oral projects (Barnett, 2005). Jane Bradbury goes on to state that interviews with experts is one of the most powerful ways to use podcasting (Bradbury, 2006). At this point in time the podcast for educational benefits seems endless. "What will be important, however, is to ensure that educational podcasts-commercial or otherwise-are updated regularly to remove outdated information" (Bradbury, 2006).

Podcasting is defined by Microsoft as "personal on-demand broadcasting". If used in higher education, this on-demand product puts supplemental educational material into the hands of students in an effective and efficient manner. Students may access this information through their personal computers or ipods. Even the automobile industry has identified the potential of this technology and will equip more than $66 \%$ of this year's new automobiles with iPod compatibilities (Benno, 2006). 
Converts claim podcasting is an easy way to increase student interest in introductory courses with large student enrollments that are offered to freshmen and sophomores every year. "Students aren't interested in absorbing every word like passive sponges," states Duke professor Dr. Richard Lucic. Net generation students who grew up on music videos and video game systems frequently complain about mind-numbingly dull lectures. Podcast technology allows supplementing courses with guest speakers, topical reviews and complementary information (Tyre, 2005).

Podcasting is not without its detractors. Critics object that digitized course presentations reduce the interaction between students and professors. Parents who pay for tuition don't always believe podcast lectures provide their children the educational value they are paying for. However, "students don't expect their parents to understand. Course casting delivers traditional components of higher learning in a format kids love-most have been downloading their favorite songs onto their iPods or MP3's since high school" (Tyre, 2005).

Despite the perceived benefits, some academics are concerned that content learning decreases as students scroll between classroom lectures and rock hits. Students learn time management, scheduling, and self discipline when class attendance is required. Class attendance provides regular contact with professors, an element experts claim significantly reduces drop-out rates. Lectures focus students on course content and provide them the opportunity to ask questions, interact with each other, and interact with the instructor (Tyre, 2005).

Podcasting is gaining popularity in higher education as a medium to supplement both traditional and distance-learning curricula. According to Apple, approximately eighty percent of university students own some form of $\mathrm{mp} 3$ player and used it regularly to listen to entertainment and news podcasts. One of the primary impediments to implementing Podcasting is the perceived cost of hardware and software technologies necessary to create the products. Although significant expenditures can be made for podcasting hardware and software, it is not required. The basic requirements to initiate a podcasting program are not exorbitant. The elements consist of a personal computer, microphone, audio editing software (available at no cost from Audacity.com), web server and a website. Given that virtually every institution has computer availability, a web server and a website, a basic podcasting program can be started for very little. Faculty desiring to incorporate basic audio or audio/still image technology into their courses can do so at virtually no cost.

\section{RESEARCH METHODOLOGY}

This study was conducted at a university in Northeast Florida in the Spring Semester of 2007. The "Aviation Science for Private Pilots" course (AVS 101) was the course used for the pilot study. During the semester, the professor posted two different ten minute podcasts on the course website. Each podcast is an abbreviated lecture of that particular day's fifty-minute regular class lecture. Both podcasts were used as supplemental information only. This gave the students in AVS 101 the opportunity to hear a shortened version of that particular day's lecture with some amplifying illustrations after the class has been completed.

The AVS 101 course met for three 50-minute periods each week over the course of a 16-week semester. The spring 2007 class used for the pilot study had an enrollment of six students. The professor identified two subject matter areas in which the students have demonstrated difficulty in comprehending the material in a single 50-minute period. These areas of difficulty are "Introduction to Very High Frequency Omnidirectional Receiver (VOR) navigation", and "Aircraft Weight and Balance". After each one of the lectures identified, the professor posted a tailored voiceover PowerPoint podcast lecture on the website for the course. The students had access to this podcast information for the entire semester after the identified lectures have been given. To insure access to podcasts by all students, they are downloadable and playable on any mp3 device, students' personal computers, or computers in university computer labs on campus. Individual student participation was tracked through the monitoring feature of the Blackboard website.

Both of the previous classes used as a control group for this pilot study plus the current class had access to comparable supplemental study materials (excluding podcasts). These supplemental study materials include 
downloadable chapter PowerPoint presentations, FAA practice test sessions and individual review periods with teaching assistants.

The statistical-analysis procedures used are described in the following section.

\section{RESULTS OF THE STUDY}

Quizzes on cross country and navigation were administered to students in the fall term of 2006, when podcasting was not available. The same quizzes were given to a smaller group of students in the spring term of 2006, when podcasting was available. The following tables provide information on basic descriptive statistics for these quizzes.

Table 1

Descriptive Statistics for Cross Country Quiz

\begin{tabular}{|c|c|c|c|}
\hline Variable & Sample Size & Mean & Standard Deviation \\
\hline With Podcast & 4 & 63.8 & 22.5 \\
\hline Without Podcast & 17 & 79.1 & 11.6 \\
\hline
\end{tabular}

Table 2

Descriptive Statistics for Navigation Quiz

\begin{tabular}{|c|c|c|c|}
\hline Variable & Sample Size & Mean & Standard Deviation \\
\hline With Podcast & 4 & 77.5 & 26.3 \\
\hline Without Podcast & 17 & 81.2 & 14.1 \\
\hline
\end{tabular}

Two sample t-tests were performed to determine if there is a difference in the mean score on these two quizzes. The results of these t-tests are summarized in the following tables.

Table 3

Two-Sample T-Test Results for Cross Country Quiz

\begin{tabular}{|c|c|c|c|c|}
\hline Difference (With Podcast - Without Podcast) & df & Test Statistic & Critical Value (2 tail, $\boldsymbol{\alpha}=\mathbf{0 . 0 5})$ & P-Value \\
\hline-15.37 & 19 & -1.99 & \pm 2.093 & 0.062 \\
\hline
\end{tabular}

Table 4

Two-Sample T-Test Results for Navigation Quiz

\begin{tabular}{|c|c|c|c|c|}
\hline Difference (With Podcast - Without Podcast) & df & Test Statistic & Critical Value (2 tail, $\boldsymbol{\alpha}=\mathbf{0 . 0 5})$ & P-Value \\
\hline-3.68 & 19 & & \pm 2.093 & 0.695 \\
\hline
\end{tabular}

In both cases, the null hypothesis (no difference in mean score with and without podcasting) is not rejected. The sample evidence suggests that the mean score on both quizzes is not affected by the availability of podcasting.

However, it must be noted that the sample size is too small for much validity to be attributed to this result. The process will be repeated during the Fall, 2007 term when a larger student sample is available. This pilot study did verify that the methodology is properly designed to yield valid results once administered to a sufficiently large sample. 


\section{QUALITATIVE ANALYSIS}

A qualitative survey was administered to the sample class after the study was completed. This survey consisted of five questions pertaining to the supplemental podcasting materials made available to the students. All students participating in the study completed the questionnaire. The survey and the results are as follows:

Did you use the supplemental podcasts materials?

Why?

1. Yes, not too supplemental though

Why not?

1. No, because I felt proficient in the subject.

2. No, computer would not let me view.

3. No, did not have spare time or did not make time

What did you like about the podcasts?

1. User friendly

How could the podcasts be changed to make them better?

1. Good for now.

Will you use supplemental podcasts in the future?

1. Yes

2. If I need some extra help in the subject matter.

3. If I could view them.

4. When time is available.

Do you own an iPod or other MP3 device compatible with podcasts?

1. Yes

2. No

3. No

4. No

As previously indicated pilot-study sample size was very small. Consequently, validity can not be attributed to the results obtained. In the first question asked on the survey, why or why not students used the podcasts, four different responses were given. Obviously, more data needs to be collected to better understand why students will use or not supplemental podcasts.

A demonstration of the podcasts was also administered to a group of executives. The podcasts were well received by this group. However, they were concerned with background level noise in the podcasts. The consensus of the group was that the podcasts materials would be better received if the background music turned town.

\section{CONCLUSION}

The responses to the qualitative questionnaire indicate the study should be implemented to a larger sample group to effectively analyze use and perceptions of supplemental podcasting materials. The responses also indicate that the background music in the supplemental podcasting materials causes distractions and should be reduced in volume before implementing future podcasts.

While conclusions can obviously not be drawn until the research process is completed and data analyzed, it is the belief of the authors that regardless of the results of this study, other questions regarding implementation of podcasting in higher education will be revealed in the study that will lead to future research. 
Continued research subsequent to this pilot test will include a literature review of related instructional technology implementations, additional studies in subsequent classes (fall, 2007/ spring, 2008)) to obtain a larger sample size and a qualitative study to evaluate student perceptions of podcasting.

\section{REFERENCES}

1. $\quad$ Barnett, M. (2005), Tech Trends: Podcasting hits the mainstream, U.S. News \& World Report, retrieved September 7, 2006 from http://www.usnews.com.

2. Benno, Mark. Personal Communication, October, 2006.

3. Bradbury, J. (2006), Podcasts, ScienceDirect, retrieved August 31, 2006 from http://www.sciencedirect.com.

4. Brenner, S. (2005). The word podcast is a portmanteau, Today's Podcast, retrieved February 12, 2007 from http://todayspodcast.com.

5. $\quad$ Castelluccio, M. (2006). Inventing New Media - the Podcast, Strategic Finance, Vol. 87, Issue 9, p57-58.

6. Google Search, retrieved September, 2006, from www.google.com.

7. Baker, R. (2006), JU Podcasting Survey Internal Report

8. Larson, R. \& Farber, B. (2000). Statistics Picturing The World, Upper Saddle River, NJ: Prentice Hall.

9. $\quad$ Morris, T. \& Terra, E. (2006). Podcasting for Dummies, Hoboken, NJ: Wiley.

10. Tyre, P. (2005), Professor In Your Pocket, Newsweek, retrieved November 1, 2006 from http://www.msnbc.msn.com/id/10117475/site/newsweek/from/ET/.

\section{NOTES}

